\title{
Studies on AM associations in Marchantia nepalensis L. et $\mathrm{L}$.
}

\author{
Mamta Verma And Anima Langer \\ Department of Botany, University of Jammu, Jammu-180 006, Jammu \& Kashmir, India
}

\begin{abstract}
Marchantia nepalensis were studied for mycorrhizal invasion in the rhizoids and thallus. fungal hyphae/vesicles/arbuscules were recorded in all the samples. The fungal hyphae never colonized the sporophytic tissue. The fungal structures observed in M. nepalensis during the present study are similar to those reported for the plant host-arbuscular mycorrhizal fungus (AMF) interactions. Spores of seven species of Glomus have also been isolated from rhizosphere soils of M. nepalensis.
\end{abstract}

Keywords: Arbuscular mycorrhizal fungi, bryophytes, hepatics

\section{Introduction}

Bryophytes are a paraphyletic group of nonvascular plants that include mosses, liverworts and hornworts. They consist of free-living gametophytes which are fixed to soil by rhizoids, as they do not have roots (Raven 2003). Hence, the terminology of "mycothalli" is preferred (Boullard 1988) instead of "mycorrhizae" to define their association with Glomeromycota. It is proposed that the mycorrhizal symbiosis coevolved from such primitive non-vascular plants during evolution (Redecker et al. 2000). The fossil record and molecular data show that the evolutionary history of arbuscular mycorrhizal fungi (Glomales ) goes back at least to the Ordovician (460 million years ago), coinciding with the colonization of the terrestrial environment by the first land plants. At that time, the land flora only consisted of plants on the bryophytic level. Majority of the information available on the physiology and anatomy of mycorrhizae is related to the sporophyte of vascular plants. For non-vascular plant groups, on the other hand, the knowledge is still scarce.Among them, the liverworts are an important and extremely successful plant group found in all continents and environments. These plants are thought to be amongst the original colonisers of terrestrial habitats; they appear to have remained relatively unchanged through time and probably hold the key to early terrestrial diversification of land plants (Read et al., 2000 and Renzaglia et al., 2007). Some members of Marchantia are known to form mycorrhiza-like associations with AM fungi. Mycothalli (thalli invaded by fungus) of these members develop structures that are analogous to those observed in AM roots, thus indicating possible functional similarities between the two (Kottke and Nebel 2005, Ligrone et al., 2007, Nebel et al., 2004 and Read et al., 2000). In these plants, as in roots, the AM fungus grows and connects two distinct environments: within the cells of thallus as inter or intra-cellular mycelium; and externally in the soil or medium matrix, thus extending the host plant capacity to access nutrients well beyond their body limits into the soil matrix. This study is a contribution to the scarce knowledge of the association between AMF and liverworts.

\section{Material And Methods}

Monthly collections of M. nepalensis were made from various sites in Jammu and Kashmir state. These samples were collected growing under diverse habitats such as canal bank, moist soil, stone wall, cemented wall, brick wall, sandy soil and rock under shady conditions or exposed to direct sunlight (Table 1). They were scanned thoroughly for mycorrhizal associations.

Plants were scrapped out in thin patches along with adhered rhizosphere soil. Rhizoids were freed from adhering soil and washed gently under tap water. The occurrence of VAM formation and structure of the endophyte was studied after cleaning and staining of these rhizoids. For this, rhizoids were boiled in $0.01 \%$ $\mathrm{KOH}$ for 2-3 hrs, kept at room temperature for $1 \mathrm{hr}$ and then washed 3-4 times to remove $\mathrm{KOH}$; rhizoids were stained with trypan blue (25\% lactic acid, $25 \%$ phenol, $25 \%$ distilled water, $25 \%$ glycerine and a pinch of trypan blue), stained rhizoids were mounted in glycerine and observed under microscope for presence of VAM fungal hyphae, vesicles and arbuscules which were later photographed using NIKON ECLIPSE 400 (Japan) camera.

Lki8ui Structural details of mycorrhiza: Structural details of mycorrhiza were studied from the thin vertical sections of thallus cut manually. Sections were kept in $0.001 \% \mathrm{KOH}$ for 30 seconds, stained in a drop of trypan blue for 2 minutes and mounted in a drop of glycerine. Slides were then sealed, waxed and photographed. In order to study the sporophytic tissue, V.S. passing through mature female receptacles with sporophytes was studied, using the same protocol. 
Isolation of VAM spores from rhizosphere soil: VAM fungal spores were isolated by following the technique standardized by Gerdemann and Nicolsan (1963).

$10 \mathrm{gm}$ of air dried rhizosphere soil was taken in a beaker and in $500 \mathrm{ml}$ of water. This suspension was then stirred for few minutes, following which the coarse particles were allowed to settle down. Thereafter, the soil solution was passed through the sieves of mesh nos. 50, 100 and 300 placed in ascending order. The contents of each mesh were washed and suspended in water in separate beakers. Spores being lighter floated on water surface. Spore suspension was gradually stirred and then filtered through Whatman Filter paper No.1. The VAM fungal spores formed a distinct ring on the filter paper. Spore ring was then observed under stereo microscope. VAM spores could be easily distinguished from the soil particles by their characteristic hyaline to coloured subtending hyphae and wall. These spores were picked up with a needle and transferred onto a slide They were mounted in Hoyer's medium (distilled water $50 \mathrm{ml}$, gum arabic $30 \mathrm{gm}$, chloral hydrate $200 \mathrm{gm}$ and glycerol $20 \mathrm{ml}$ ) and studied under microscope. Spore size, shape and wall pattern were parameters used for taxonomic identification.

The number of spores per $10 \mathrm{gm}$ of soil sample was counted and for each sample, averages of 3 replicates were taken.

\section{Results}

Mycorrhizal associations were found to be present in all the studie samples. In all invaded samples an aseptate fungus was regularly found associated with smooth walled (Fig. 1a) as well as tuberculated (Fig. 1b) rhizoids. Mycorrhizal colonization frequency however was much higher in smooth walled rhizoids (Table1). Usually one (Fig. 1a), two (Fig. 1c), or rarely three (Fig. 1d) hyphal strands ran across the rhizoids. Septa were rarely observed in case of aged hyphae (Fig. 1e). Fungus displayed Y- (Fig. 1e) and H- connections (Fig. 1f) quite frequently. It exhibited different growth patterns, such as coils (Fig. 1g), irregular growth pattern (Fig. 1h) and loops (Fig. 1i). Loops were also observed in swollen part of rhizoids (Fig. 1j).

Darkly stained vesicles were formed at the terminal position on the hyphae, which showed diversity in

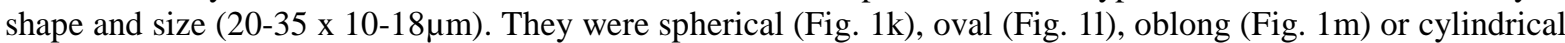
(Fig. 1n).

Sporophytic tissue was found absolutely free of mycorrhizal invasion (Fig. 1o)

Fungal endophyte in thallus. All the populations where fungus invaded rhizoids were investigated for the occurrence of mycelium in thallus as well. In every plant examined V. S. of the thallus showed fungal invasion in the cells comprising the middle and upper regions of the storage zone (Fig. 2a). Photosynthetic tissue and uppermost 1-2 layers of storage zone were invariably free of the invasion. Fungus was not found even in the lower 5-12 layers of the storage zone (Fig. 2b). Some cells of the storage zone were completely filled with hyphae (Fig. 2c) and arbuscules (Fig. 2d). A developing arbuscule had a main trunk-like hypha which formed fine branching (Fig. 2e). These hyphae got collapsed in developed arbuscule (Fig. 2f).

Spores belonging to a total of seven species of Glomus (G. constrictum, G. convolutum, G. geosporum, G. macrocarpum, G. multicaule, G. pallidum and G. segmentatum) were isolated from the rhizosphere soils of all the populations' exihibiting mycorrhiza.

\section{Discussion}

Bryophytes represent a large group of plants which are believed to have been the first to inhabit the land (Groth-Malonck et al., 2004). The Vesicular Arbuscular Mycorrhizal (VAM) fungi are also believed to have appeared around the same period (Redecker et al., 2000). The strong congruency between the origin of liverworts and VAM fungi has suggested that the symbiotic fungal associations of liverworts are the possible ancestors of mycorrhizae (Nebel et al., 2004).

Bryophytes being the first group to exploit land plant habit, must have acquired a large number of morpho-anatomical, physiological and reproductive modifications which conferred on them, the selective adaptations under the changed environmental conditions. One of these adaptations it seems was development of symbiosis with fungi, before the evolution of true mycorrhiza. It is opined that fungi originally switched from the gametophytes of liverworts to the roots of sporophytes of tracheophytes (Redecker et al., 2000).

Mycorrhizal fungi are widely distributed and are reported in 2,537 angiosperm, 84 gymnosperm, 224 pteridophyte and 66 bryophyte species (Wang and Qiu, 2006). The most common type of mycorrhizal association is VAM that involves members of Glomeromycota which are characterized by aseptate hyphae, vesicles and arbuscules. In bryophytes, VAM have been reported for hepatics (Duckett and Read, 1995; Ligrone and Lopes, 1989; Pocock and Duckett 1984, 1985; Stahl, 1949; Turnau et al., 1998), hornworts (Ligrone, 1988) and mosses (Parke and Linderman, 1980; Rabatin, 1980). It is not; however, always clear whether the fungus participating in the symbiosis belongs to Glomales. Rabatin (1980) reported ecological aspects of the relationship between the VAM fungus-Glomus tenuis and moss Pogonatum but, the credit goes to Schößler 
(2000) who for the first time reported arbuscular mycorrhiza- like symbiosis between identified fungus, Glomus clarodium belonging to the Glomales and a hornwort Anthoceros punctatus. Barring this, there is no other report available in the literature for specific associations between bryophytes and identified species of Glomus.

Fungi invading M. nepalensis have many of the morphological features of VAM endophytes. Their aseptate nature clearly indicates that they neither belong to the group basidiomycetes nor ascomycetes. The course of invasion observed presently exhibit similarities to VAM invasion in plant roots as the growth of the fungus was limited in the outer tissues and proliferated mainly in the middle of midrib region. Some earlier workers have, however, recorded the mycelium confined to the gametophyte and restricted to a zone of tissue below the air canals in Marchantia nepalensis (Chaudhari and Rajaram, 1925). It is worthwhile to mention that during present study a total of seven species of Glomus (G. constrictum, G. convolutum, G. geosporum, G. macrocarpum, G. multicaule, G. pallidum and G. segmentatum) were isolated from the rhizosphere soil of Marchantia nepalensis.

The recognition of this symbiosis depends on the identification of the typical intercellular hyphae, intracellular hyphae, vesicles and arbuscules (Brundrett, 2002; Peterson et al., 2004). During present study, all these structures were observed frequently, except the intercellular hyphae. Their absence can easily be understood because the rhizoids are unicellular and secondly, the cells of storage zone of thallus are compactly arranged. Of the remaining three structures, vesicles were associated with rhizoids, whereas arbuscules were formed inside the parenchymatous cells of thallus. Intracellular hyphae, however, occurred in both, rhizoids as well as the thallus cells. In M. nepalensis the invasion seems similar to the "Paris" type of AM (Gallaud, 1905) as the hyphae are entirely intracellular. Arbuscules formed by the endophytes were also not of the classical branching form seen in linear Arum-type infections, but rather a mass of very fine dichotomously branching hyphae forming a 'fuzz' around the main trunk hyphae.

"Paris" type is the most common AM growth form in bryophytes, ferns and gymnosperms which lack intercellular spaces in parenchyma tissue (Smith \& Smith, 1997). Some aspects of M. nepalensis symbioses such as invasion through rhizoids, absence of fungal invasion in photosynthetic tissue and uppermost 1-2 layers of storage zone were similar to those reported in Conocephalum conicum by Ligrone \& Lopes (1989). However, there were differences in the cytology of the invasion in the thallus as vesicles were not found in the lower region of storage zone during present study. Absence of vesicles in the storage zone was also reported by Russell and Bulman (2005) in M. foliacea. Notably, the upper arbuscular zone lies directly beneath the photosynthetic epidermal cells (Fig. 2b) and is therefore close to the source of organic carbon. The invading endophyte possibly establishes and maintains invasion by means of longitudinally growing hyphae in the lower zone, while active metabolic exchange occurs in the upper zone.

Arbuscule completes its development in 4 or 5 days (Brundrett et al., 1996) and remains active for 415 days (Cox and Tinker, 1976; Carling and Brown, 1982). In M. nepalensis arbuscules remain active only for 4-7 days. Vesicles are rich in lipids and believed to serve as endophytic storage organs. They are formed only by members of Glomaceae and Acaulosporacae (Abbott, 1982; McGee, 1986). The vesicles develop as terminal or intercalary swellings of the hyphae. They are also known to display diversity in their shapes. Cooper (1976) reported elongated, spherical, oval, lobed, reniform and cylindrical vesicles among pteridophytes. He also reported thick walled vesicles resembling endophytic spores. During present study spherical, oval, oblong and cylindrical vesicles were observed in the rhizoids. Ligrone et al. (2007), however, reported vesicles in rhizoids as well as thallus of Marchantia nepalensis. The other species of genus Marchantia reported to have mycorrhizal association are M. foliacea (Russel and Bulman, 2005) and M. berteroana (Ligrone et al., 2007).

\section{References}

[1]. Abbott, L.K. 1982. Comparative anatomy of vesicular- arbuscular mycorrhiza formed on subterranean clover. Aus. J. Bot. 30 485-499.

[2]. Bago, B., Azcón-Aguilar, C., Goulet, A. and Piché, Y. 1998. Branched absorbing structures (BAS): a feature of the extraradical mycelium of symbiotic arbuscular mycorrhizal fungi. New Phytol 139: 375-388.

[3]. Boullard, B. 1979. Conside“ rations sur la symbiose fongique chez les Pteridophytes. Syllogeus No. 19

[4]. Brundrett, M.C. 2002. Coevolution of roots and mycorrhizas of land plants. New Phytologist. 154: $275-304$

[5]. Brundrett, M.C., Bougher, N., Dell, B., Grove, T., and Malajczuk, N. 1996. Working with mycorrhizas in forestry and agriculture. In: Australian Centre for International Agricultural Research Monograph 32, Canberra, Australia, pp. 179-183.

[6]. Carling, D.E. and Brown, M.F. 1982. Anatomy and physiology of VAM roots. Phytopathology. 72: 1108-1114.

[7]. Chaudhari, H., and Rajaram, K. 1925. A study of the fungal endophyte of Marchantia nepalensis. Proceedings Plant Sciences. 13(4): 255-260.

[8]. Cox, G. and Tinker, P.B. 1976. Translocation and transfer of nutrients in vesicular arbuscular mycorrhizas. I. The arbuscules and phosphorus transfer: a quantitative ultrastructural study. New Phytol. 77: 371-378.

[9]. Duckett, J.G., and Read, D.J. 1995. Ericoid mycorrhizas and rhizoid ascomycete associations in liverworts share the same mycobiont: Isolation of the partners and resynthesis of the associations in vitro. New Phytologist. 129: 439 - 447.

[10]. Gallaud, I. 1905. E“ tudes sur les mycorhizes endotrophes. Rev. Ge“n. Bot. 17: 7-43.

[11]. Gerdemann, J.W. and Nicolson, T.W. 1963. Spores of mycorrhizal Endogone species extracted from soil by wet-sieving and decanting method. Transaction of British Mycological Society. 46: 235-245. 
[12]. Groth-Malonck, M., Pruchner, D., Grewe, F. and Knoop, V. 2004. Ancestors of trans -splicing mitochondrial introns support serial sister group relationships of hornworts and mosses with vascular plants. Molecular Biology and Evolution. 22: 117-125.

[13]. Harley, J.L. 1983. A check-list of mycorrhiza in the British flora. New Phytologist. 105 (Supplement 2), 1-102.

[14]. Kottke, I. and Nebel, M. 2005. The evolution of mycorrhiza-like associations in liverworts: an update. New Phytologist. 167: $330-334$.

[15]. Ligrone, R., Carafa, A., Bonfante, P., Bianciotto, V. and Duckett, J.G. 2007. Glomeromycotean associations in liverworts: A molecular, cytological and taxonomical survey. American Journal of Botany. 94 : 1756 - 1777.

[16]. Ligrone, R. 1988. Ultrastructure of a fungal endophyte in Phaeoceros laevis (L.) Prosk. (Anthoceratophyta). Bot. Gaz. 149: 92 100.

[17]. Ligrone, R. and Lopes, C. 1989. Cytology and development of a mycorrhiza-like infection in the gametophyte of Conocephalum conicum (L.) Dum. (Marchantiales, Hepatophyta). New Phytol. 111: 423-433.

[18]. McGee, P.A. 1986. Further sporocarpic species of Glomus (Endogonaceae) from South Australia. Trans. Br. Mycol. Soc.87 123-129.

[19]. Nebel, M., Kreier, H.P., Pressing, M., Weib, M.A. and Kottke, I. 2004. Symbiotic fungal associations with liverworts are the possible ancestors of mycorrhizae. In R. Agerer, H. Piepenbring, and P. Blanz (eds.), Frontiers in basidiomycete mycology, 339360. HIWVerlag, Ecking, Germany.

[20]. Parke, J.L. and Linderman, R.G. 1980. Association of vesicular-arbuscular mycorrhizal fungi with the moss Funaria hygrometrica. Can. J. Bot. 58: 1898-1904.

[21]. Peterson, R.L., Massicotte, H.B. and Melville, L.H. 2004. Mycorrhyzas: anatomy and cell biology. NRC Research Press, Ottawa, Quebec,Canada.

[22]. Pocock, K., and Duckett, J.G. 1984. A comparative ultrastructural analysis of the fungal endophytes in Cryptothallus mirabilis Malm. and other British thalloid hepatics. Journal of Bryology. 13: 227-233.

[23]. Rabatin, S.C. 1980. The occurrence of vesicular-arbuscular mycorrhizal fungus Glomus tenuis with moss. Mycologia. 72: 191195.

[24]. Rayner, M.C. 1927. Mycorrhiza: An accout of non pathogenic infection by fungi in vascular plants and Bryophytes. New Phytologist. Reprint no. 15. London, UK.

[25]. Read, D.J., Duckett, J.G., Francis, R., Ligrone, R. and Russell, A. 2000. Symbiotic fungal associations in lower land plants. Philosophical Transactions of the Royal Society of London. 355: 815-831.

[26]. Redecker D, Kodner R, Graham LE. 2000. Glomalean fungi from the Ordovician. Science. 289: 1920-1921.

[27]. Renzaglia, K. S., Schuette, S., Duff, R.J., Ligrone, R., Shaw, A.J., Mishler, B.D. and J. G. Duckett. 2007 Bryophyte phylogeny: Advancing the molecular and morphological frontiers.The Bryologist 110(2): 179-213.

[28]. Russell, J. and Bulman, S. 2005. The liverwort Marchantia foliacea forms a specialized symbiosis with arbuscular mycorrhizal fungi in the genus Glomus. New Phytologist. 165: 567-579.

[29]. Schüßler, A. 2000. Glomus claroideum forms an arbuscular mycorrhiza like symbiosis with the hornwort Anthoceros punctatus Mycorrhiza. 10: 15-21.

[30]. Smith, S.E. and Read, D.J. 1997. Mycorrhizal Symbiosis, 2nd ed. Academic Press, Cambridge, UK.

[31]. Smith, F.A. and Smith, S.E. 1996. Mutualism and parasitism: diversity in function and structure in the 'arbuscular'(VA) mycorrhizalsymbiosis. Advances in Botanical Research 22:1-43.

[32]. Stahl, M. 1949. Die Mycorrhiza der Lebermoose mit besonderer Berucksichtigung der thallosen Formen. Planta. 37: 103-148.

[33]. Turnau, K., Wenhrynowicz, O. and Micrzenska, M. 1998. Ericoid mycorrhizas in heavily polluted environments-stratagies of plants, liverworts and fungi. Proceedings of the Second International Conference on trace elements. Katowice, Poland: Centre for studies on Human and Natural Environment, 27-32.

[34]. Wang, B. and Qiu, Y.L. 2006. Phylogenetic distribution and evolution of mycorrhizas in land plants. Mycorrhiza. 16: 299-363 